\title{
Nurse Level of Education, Quality of Care and Patient Safety in the Medical and Surgical Wards in Malaysian Private Hospitals: A Cross-sectional Study
}

\author{
Hamzah Abdul Rahman ${ }^{1}$, Mu'taman Jarrar ${ }^{1} \&$ Mohammad Sobri Don ${ }^{1}$ \\ ${ }^{1}$ College of Business, Universiti Utara Malaysia, Kedah, Malaysia \\ Correspondence: Hamzah Abdul Rahman, PhD, College of Business, Universiti Utara Malaysia, PO Box 06010, \\ SBM, COB, UUM, Sintok, Kedah, Malaysia. Tel: 60-13-390-3837. E-mail: hamzahd@uum.edu.my
}

Received: March 27, 2015 Accepted: April 15, 2015 Online Published: April 23, 2015

doi:10.5539/gjhs.v7n6p331 URL: http://dx.doi.org/10.5539/gjhs.v7n6p331

\begin{abstract}
Background and Objective: Nursing knowledge and skills are required to sustain quality of care and patient safety. The number of nurses with Bachelor degrees in Malaysia is very limited. This study aims to predict the impact of nurse level of education on quality of care and patient safety in the medical and surgical wards in Malaysian private hospitals.

Methodology: A cross-sectional survey by questionnaire was conducted. A total of 652 nurses working in the medical and surgical wards in 12 private hospitals participated in the study. Multistage stratified simple random sampling performed to invite nurses working in small size (less than 100 beds), medium size (100-199 beds) and large size (over than 200) hospitals to participate in the study. This allowed nurses from all shifts to participate in this study.

Results: Nurses with higher education were not significantly associated with both quality of care and patient safety. However, a total 355 (60.9\%) of respondents who participated in this study were working in teaching hospitals. Teaching hospitals offer training for all newly appointed staff. They also provide general orientation programs and training to outline the policies, procedures of the nurses' roles and responsibilities. This made the variances between the Bachelor and Diploma nurses not significantly associated with the outcomes of care.

Conclusions: Nursing educational level was not associated with the outcomes of care in Malaysian private hospitals. However, training programs and the general nursing orientation programs for nurses in Malaysia can help to upgrade the Diploma-level nurses. Training programs can increase their self confidence, knowledge, critical thinking ability and improve their interpersonal skills. So, it can be concluded that better education and training for a medical and surgical wards' nurses is required for satisfying client expectations and sustaining the outcomes of patient care.
\end{abstract}

Keywords: nurse level of education, teaching hospitals, hospital size, training, quality of care, patient safety, outcomes of care

\section{Introduction}

Institute of Medicine (IOM) in their report To 'Err Is Human' reported that 98,000 deaths occurred annually in the United States of America as result of medical errors (IOM, 2000). In Australia, adverse events occurred for $17 \%$ of all admitted patients (Wilson et al., 1995). However, in Malaysia the demand and cost of care is increasing while lack of resources threaten sustainable performance of Malaysian health system $(\mathrm{MOH}, 2011 \mathrm{a})$. Learning is essential to create positive and healthy work environments (Baumann, 2007), which can improve patient care outcomes (Aiken et al., 2012). Learning organizations are those which support professional development and knowledge sharing for long life learning (Baumann, 2007). Learning organizations are creating, acquiring and transferring knowledge (Wheelen, Hunger, Hoffman, \& Bamford, 2015), and convert it to improve their performance for solving functional problems (Yang, B., Watkins, K. E. Marsick, 2004), which results in high service quality and staff satisfaction (Pantouvakis \& Mpogiatzidis, 2013). Chen and Kuo (2011) show that there is a significant relationship between learning organizations and quality control; group learning affects quality control and improves the performance of hospitals. Many studies found that higher educated nurses are more associated with patient safety and quality of care (Aiken, Clarke, Cheung, Sloane, \& Silber, 2003; Cramer 
et al., 2011; Estabrooks et al., 2005; Tourangeau et al., 2006, 2007). For instance, Tourangeau et al. (2007) found that increasing the proportion of bachelorette prepared nurses by $10 \%$ led to decreased mortality by nine cases among one thousand discharged patients. Thus, hospital managers should prepare and attract better educated nurses which can better navigate today's healthcare complexity to deliver best practices consistent with current evidence. However, nurses with Bachelor degree were limited in Malaysia (Yaakup, Eng, \& Shah, 2014). According to the Malaysian Ministry of Health (MOH) Annual Report (2011) the performance of nurses working in private hospitals were lower than nurses working in public hospitals (MOH, 2011b). Thus, the main purpose of the study is to explore the effect of nurse level of education on quality of care and patient safety in Malaysian private hospitals.

\section{Methodology}

\subsection{Design}

A cross-sectional survey was conducted at the individual nurse level of analysis of nurses working in the medical and surgical wards in Malaysian private hospitals. Medical and surgical wards were chosen because they deliver multidisciplinary level of care such as medical cardiology, gastroenterology, urology, oncology, nephrology, orthopedics, and ear, nose and throat care (Coetzee, Klopper, Ellis, \& Aiken, 2013).

\subsection{Sampling}

Multistage stratified simple random sampling was performed to collect data from nurses working in all shifts in the medical and surgical wards. The stratified random sampling offers more homogeneity within the stratum and higher heterogeneity among group of strata which produce a "mirror image of the population" (Sekaran \& Bougie, 2010). The simple random sampling of each stratum ensure each hospital and nurse have an equal chance to be chosen randomly (Sekaran \& Bougie, 2010). The inclusion criteria of nurses are those nurses' registered by the $\mathrm{MOH}$ Malaysia and delivering direct inpatient care in the medical and surgical wards. The inclusion criteria of hospitals are those registered in the Association of Private Hospitals of Malaysia. The number of beds used to evaluate hospital size according to the current nursing literature as follows (Gok \& Sezen, 2013; K. H. Lee \& S. B. Yang, 2009):

1) Small size: less than 100 beds.

2) Medium size: 100-199 beds.

3) Large size: over than 200 beds.

\subsection{Operationalization and Measurement}

The outcomes of care reflect the end result of the caring process (Harvey, 2004). The outcomes of care in the study consist of two dependent variables: quality of care and patient safety. Items used of measuring the study variables were internationally validated (Aiken et al., 2012; Coetzee et al., 2013; Van Bogaert, Clarke, Vermeyen, Meulemans, \& Van de Heyning, 2009). For measuring quality of care, nurses were asked to grade the overall quality of care in the last shift and during the last year (Van Bogaert, Meulemans, Clarke, Vermeyen, \& Van de Heyning, 2009). Furthermore, nurses were asked whether they will recommend the hospital to their friends and family if they need hospital care or as good place to work (Coetzee et al., 2013).

Patient safety is prevention of any potential harm for the hospitalized patients (Groene et al., 2010). According to the current nursing literature, the most common potential harm in the medical and surgical wards are nosocomial infection, pressure ulcer, patient fall, medication errors, readmission and patient and family complaints (Laschinger \& Leiter, 2006; Van Bogaert et al., 2014; Weingart et al., 2011). Thus, nurses were asked to report their degree of agreement of the overall rating of the frequency of these events. Furthermore, nurses were asked to rate the overall patient safety in their unit using five point Likert scale, which is validated from the Agency for Healthcare Research and Quality survey of patient safety (Aiken et al., 2012; Coetzee et al., 2013; You et al., 2013). The nurse level of education was measured by asking the nurse to indicate his/her education and choosing among three categories; Bachelor, Diploma or others (Boumans, Landeweerd, \& Visser, 2004).

Back-To-Back translation and pilot study are performed to make sure that questionnaire is reliable and free of mistakes, wrong wording or changes in the meaning. The coefficient of Cronbach's alpha is indicated internally consistent and the adequate instrument used in the study. The Cronbach's alpha coefficient of quality of care and patient safety was 0.75 and 0.85 respectively, which are above the recommended level of 0.70 (Pallant, 2011; Sekaran \& Bougie, 2010). Multiple regression analysis performed using the SPSS software version 21.0 to investigate the impact of nurse level of education on quality of care and patient safety at $p<0.05$ level of significance. 


\section{Results}

A total 652 nurses working in the medical and surgical wards with $61.8 \%$ response rate participated in the study from 12 private hospitals in Malaysia. The demographic characteristics of respondents indicated that $99.0 \%$ of nurses were Malaysian, and $97.6 \%$ of nurses were female. The respondents in the study were from the three ethnic groups: $60.0 \%$ Malay, $21.6 \%$ Chinese and $14.2 \%$ Indian. In term of employment status, $98.1 \%$ were full time while only $1.9 \%$ were part time nurses. A total $60.9 \%$ of nurses were working in teaching hospitals, while $39.1 \%$ from non-teaching hospitals. The teaching hospitals in the study refer to those hospitals awarding a degree of nursing. Additionally, $84.6 \%$ of respondents held a Diploma in nursing, while only $10.3 \%$ hold a Bachelor degree in nursing and 5.1\% other (the others included a nurse who had an associate degree in nursing or higher education).

The nurse level of education construct include three categories, thus $\mathrm{j}-1$ dummy variables to capture all information for each category required to be compared with the reference group (Cohen, Cohen, West, \& Aiken, 2003; Hardy, 1993; West, Aiken, \& Krull, 1996). The reference group should be well defined in order to clearly interpret the study result. Furthermore, it should contain a sufficient number of respondents and should not be "others category" (Cohen et al., 2003; Hardy, 1993; West et al., 1996). Thus, the reference group was nurses with Diploma. Multiple regression analysis of the effect of nurse level of education on the outcomes of care explored in two regression models. The first model was explored the effect of nursing education on quality of care, whereas the second regression model was explored the effect of nursing education on patient safety.

\subsection{Model 1: Nurse Level of Education and Quality of Care}

Nurse level of education included two dummy variables. Table 1 shows the multiple regression analysis result of its impact on quality of care in order to test the hypothesis:

The alternative hypothesis H1: nurse level of education is associated with quality of care.

The null hypothesis $\mathrm{H}_{0}$ : nurse level of education is not associated with quality of care.

Table 1. Regression analysis result of nurse level of education on quality of care

\begin{tabular}{|c|c|c|c|c|c|}
\hline Variables & $\begin{array}{l}\text { Unstandardized } \\
\text { Coefficients B }\end{array}$ & Std. Error & $\begin{array}{c}\text { Standardized } \\
\text { Coefficients } \beta\end{array}$ & $\mathrm{t}$ & Sig. \\
\hline (Constant) & 3.74 & 0.03 & & 146.60 & 0.00 \\
\hline \multicolumn{6}{|l|}{ Diploma (R) } \\
\hline Bachelor degree & -0.07 & 0.08 & -0.04 & -0.86 & 0.39 \\
\hline Other education & 0.12 & 0.11 & 0.05 & 1.11 & 0.27 \\
\hline $\mathrm{R} 2$ & 0.004 & & & & \\
\hline F value & 1.07 & & & & \\
\hline Significance of $F$ value & 0.34 & & & & \\
\hline
\end{tabular}

Significant level: ***: $\mathrm{p}<0.001 ; * *: \mathrm{p}<0.01 ; *$ : $<0.05$. (R): Reference group.

The result of the regression analysis as shown in Table 1 revealed that $\mathrm{F}=1.07$ and $\mathrm{P}$ value $=0.34$ indicated that the study failed to reject the null hypothesis $\mathrm{H}_{0}$. So, the relationship of nurse level of education is not significantly affecting quality of care. The $\mathrm{R}^{2}$ indicates that nurse level of education variable predicted only 0.004 of variances in quality of care and not significant at level $p<0.05$. Moreover, nurses with Bachelor degree $(\mathrm{B}=-0.07, \mathrm{t}=-0.86, \mathrm{p}=0.39)$ are not significantly affecting quality of care at $\mathrm{p}<0.05$ significance level compared with those have a Diploma. Thus, the hypothesis H1 is not supported.

\subsection{Model 2: Nurse Level of Education and Patient Safety}

Table 2 provided the result of multiple regression analysis of the nurse level of education on patient safety in order to test the hypothesis:

The alternative hypothesis $\mathrm{H} 2$ : nurse level of education is associated with patient safety.

The null hypothesis $\mathrm{H} 2_{0}$ : nurse level of education is not associated with patient safety. 
Table 2. Regression analysis result of nurse level of education on patient safety

\begin{tabular}{|c|c|c|c|c|c|}
\hline Variables & $\begin{array}{l}\text { Unstandardized } \\
\text { Coefficients B }\end{array}$ & Std. Error & $\begin{array}{c}\text { Standardized } \\
\text { Coefficients } \beta\end{array}$ & $\mathrm{t}$ & Sig. \\
\hline (Constant) & 3.59 & 0.03 & & 135.42 & 0.00 \\
\hline \multicolumn{6}{|l|}{ Diploma (R) } \\
\hline Bachelor degree & -0.05 & 0.08 & -0.03 & -0.62 & 0.53 \\
\hline Other education & -0.03 & 0.11 & -0.01 & -0.26 & 0.80 \\
\hline R2 & 0.001 & & & & \\
\hline$F$ value & 0.22 & & & & \\
\hline Significance of $F$ value & 0.81 & & & & \\
\hline
\end{tabular}

Significant level: ***: $\mathrm{p}<0.001 ; * *: \mathrm{p}<0.01 ; *: \mathrm{p}<0.05$. (R): Reference group.

The result of the regression analysis as shown in Table 2 revealed that $\mathrm{F}=0.22$ and $\mathrm{P}$ value $=0.81$ indicated that the study failed to reject the null hypothesis $\mathrm{H} 2{ }_{0}$. So, nurse level of education is not significantly affecting patient safety. The $\mathrm{R}^{2}$ indicates that nurse level of education variable predicts only 0.001 of variances in patient safety and not significant at level $\mathrm{p}<0.05$. Moreover, nurses with bachelor degree $(\mathrm{B}=-0.05, \mathrm{t}=-0.62, \mathrm{p}=0$. 53) is not significant affecting patient safety at $\mathrm{p}<0.05$ significance level compared with those have a Diploma. Thus, the hypothesis $\mathrm{H} 2$ is not supported.

\section{Discussion}

Regression analysis of the impact of nurse level of education as reported in Table 1 and Table 2 indicated insignificant impact on both quality of care and patient safety at $p<0.05$ significance level. These findings are inconsistent with previous studies. Many studies found that nurses with higher education are significantly associated with delivering high quality of care and patient safety (Aiken et al., 2003; Cramer et al., 2011; Estabrooks et al., 2005; Tourangeau et al., 2007, 2006). For instance, Tourangeau et al (2007) found that increasing the proportion of bachelorette nurses by $10 \%$ significantly led to decrease in the mortality rate by nine cases among a thousand discharged patients (Tourangeau et al., 2007). Furthermore, highly educated and involved healthcare providers help to be more patient centered in order to improve quality of care and patient safety (Ferguson et al., 2007). However, respondents demographics discussed in section 3 revealed that 355 $(60.9 \%)$ of respondents who participated in the study worked in teaching hospitals. In teaching hospitals, all new staff should given general orientation program and training to outline the policies, procedures and their role and responsibilities in order to improve quality of patient care (Scott, Poole, \& Jayathissa, 2008). So, the conclusion is that Malaysian private hospitals have structured nursing orientation and training program of newly appointed staff, which made the variances of nurse level of education insignificantly associated with quality of care and patient safety. This was supported by a comparative study between the Malaysian and the Australian healthcare systems, where there were compulsory training programs for staff prior to entry into the general practice and a continuous professional development programs which are important for sustaining the outcomes of care (Khoo \& Richard, 2002).

This point of view was supported by a number of studies in the Malaysian hospitals (Chiu, 2006; Ludin, Parker, \& Arbon, 2014). A study conducted in four Malaysian public hospitals supported this point of view (Ludin et al., 2014). Teaching hospitals had commitment to teaching and training of their staff (Ludin et al., 2014). Furthermore, in Malaysia there is a four weeks post registration training program conducted widely as a venture between an Australian university and Malaysian private hospitals (Chiu, 2005). The post registration training program for nurses in Malaysia help to upgrade the Diploma nurses (Chiu, 2006). Training program increased their self confidence, knowledge, critical thinking ability and their interpersonal skills (Chiu, 2006). So, it can be conclude that better education and training for a medical and surgical wards staff nurses is required for satisfying client expectations, sustaining the outcomes of care and improving quality and patient safety. Training and learning by providing skills for healthcare professionals is a key for optimizing quality and patient safety (Scott et al., 2008; Siriwardena, 2006; Valero et al., 2009). 


\section{Conclusion}

There is no significant effect of the level of education of nurses working in the medical and surgical wards in Malaysian private hospitals because they have structured training programs of their appointed staff. This made the variances of nurse level of education insignificantly associated with quality of care and patient safety. Training and learning by providing skills for healthcare professionals is a key for optimizing quality and patient safety. Thus, hospital management should be prepared to educate nurses in order to optimize the outcomes of patient care. Furthermore, all new staff should be given a general orientation program and training to outline the policies, procedures and their role and responsibilities in order to improve quality of patient care. However, education and training alone is not effective to change practice. Thus, multi-level interventions are required in addition to education and training in order to sustain the outcomes of care. Further research is recommended to include staffing and the work environment factors to predict the outcomes of care.

\section{Acknowledgments}

Grant for the research provided by Universiti Utara Malaysia (UUM). The authors acknowledge Prof. Dr. Mohammad Alghoul from the National University of Malaysia and Dr. Liana Orsolini-Hain PhD, RN and Care Delivery and Advanced Practice Systems Consultant in Bon Secours Health System, Inc (BSHSI) for their guidance and support for this work.

\section{References}

Aiken, L. H., Clarke, S. P., Cheung, R. B., Sloane, D. M., \& Silber, J. H. (2003). Educational levels of hospital nurses and surgical patient mortality. American Medical Association, 290(12), 1617-1623.

Aiken, L. H., Sermeus, W., Van den Heede, K., Sloane, D. M., Busse, R., Mckee, M., ... Smith, H. L. (2012). Patient safety, satisfaction, and quality of hospital care: Cross sectional surveys of nurses and patients in 12 countries in Europe and the United States. British Medical Journal, 344(e1717), 1-14. http://dx.doi.org/10.1136/bmj.e1717

Baumann, A. (2007). Positive Practice Environments: Quality Workplaces (p. 61). Geneva (Switzerland): ICN-International Council of Nurses. Retrieved http://www.icn.ch/images/stories/documents/publications/ind/indkit2007.pdf

Boumans, N. P. G., Landeweerd, J. A., \& Visser, M. (2004). Differentiated practice, patient-oriented care and quality of work in a hospital in the Netherlands. Scandinavian journal of caring sciences, 18(1), 37-48. Retrieved from http://www.ncbi.nlm.nih.gov/pubmed/15005662

Chen, I.-C., \& Kuo, M.-H. C. (2011). Quality improvement: perspectives on organizational learning from hospital-based quality control circles in Taiwan. Human Resource Development International, 14(1), 91-101. http://dx.doi.org/10.1080/13678868.2011.542901

Chiu, L. H. (2005). Motivation for nurses undertaking a post-registration qualification in Malaysia. International Nursing Review, 52, 46-51. http://dx.doi.org/10.1111/j.1466-7657.2004.00415.x

Chiu, L. H. (2006). Malaysian Registered Nurses' Professional Learning. International Journal of Nursing Education Scholarship, 3(1).

Coetzee, S. K., Klopper, H. C., Ellis, S. M., \& Aiken, L. H. (2013). A tale of two systems--nurses practice environment, well being, perceived quality of care and patient safety in private and public hospitals in South Africa: a questionnaire survey. International journal of nursing studies, 50(2), 162-173. http://dx.doi.org/10.1016/j.ijnurstu.2012.11.002

Cohen, J., Cohen, P., West, S., \& Aiken, L. (2003). Applied multiple regression/correlation analysis for the behavioral sciences. Lawrence Erlbaum Associates. Retrieved from http://books.google.com/books?hl=en\&lr=\&id=gkalyqTMXNEC\&oi=fnd\&pg=PP1\&dq=Applied+multiple + regression/+correlation + analysis + for+the+behavioral+sciences\&ots $=$ tQCV02 $\mathrm{mbch} \&$ sig $=\mathrm{kbtLMNFzquJw}$ myNgVxNV-Owh07s

Cramer, M. E., Jones, K. J., \& Hertzog, M. (2011). Nurse staffing in critical access hospitals: Structural factors linked to quality care. Journal of nursing care quality, 26(4), 335-43. http://dx.doi.org/10.1097/NCQ.0b013e318210d30a

Estabrooks, C. A., Midodzi, W. K., Cummings, G. G., Ricker, K. L., \& Giovannetti, P. (2005). The impact of hospital nursing characteristics on 30-day mortality. Nursing Research, 54(2), 74-84. 
Ferguson, L., Calvert, J., Davie, M., Fallon, M., Ferd, N., Gerbach, V., \& Sinclair, L. (2007). Clinical leadership: Using observations of care to focus risk management and quality improvement activities in the clinical setting. Contemporary nurse, 24(2), 212-224.

Gok, M. S., \& Sezen, B. (2013). Analyzing the ambiguous relationship between efficiency, quality and patient satisfaction in healthcare services: the case of public hospitals in Turkey. Health policy (Amsterdam, Netherlands), 111(3), 290-300. http://dx.doi.org/10.1016/j.healthpol.2013.05.010

Groene, O., Klazinga, N., Wagner, C., Arah, O. a, Thompson, A., Bruneau, C., \& Suñol, R. (2010). Investigating organizational quality improvement systems, patient empowerment, organizational culture, professional involvement and the quality of care in European hospitals: The "Deepening our Understanding of Quality Improvement in Europe (DUQuE)" proje. BMC health services research, 10, 281. http://dx.doi.org/10.1186/1472-6963-10-281

Hardy, M. (1993). Regression with dummy variables (1st ed.). SAGE Publications Ltd. Retrieved from http://books.google.com/books?hl=en\&lr=\&id=EzLffJlYISEC\&oi=fnd\&pg=PR5\&dq=Regression+with+D ummy+variable\&ots=R81XjXqfSx\&sig=lnNBq6ol hwewjSygDJeQDJSyJTw

Harvey, R. (2004). Using clinical performance information to improve the quality of care in a specialist NHS trust. Journal of nursing management, 12(6), 427-435. http://dx.doi.org/10.1111/j.1365-2834.2004.00513.x

IOM. (2000). To Err Is Human: Bulding a Safer Health System. National Academy Press, Washington DC.

Khoo, E., \& Richard, K. (2002). Primary health care and general practice - a comparison between Australia and Malaysia. Asia-Pacific Journal of Public Health, 14(2), 59-63. Retrieved from http://aph.sagepub.com/content/14/2/59.short

Laschinger, H., \& Leiter, M. (2006). The impact of nursing work environments on patients safety outcomes. The mediating role of burnout/engagement. Journal of Nursing Administration, 36, 259-267.

Lee, K. H., Yang, S. B. C. M. (2009). The association between hospital ownership and technical efficiency in a managed care environment. Journal of Medical Systems, 33, 307-15.

Ludin, S. M., Parker, S., \& Arbon, P. (2014). A survey of Malaysian Critical Intensive Care Unit nurses' awareness of patients' transition experiences (PE) and transitional care practice (TCP). Intensive \& critical care nursing : the official journal of the British Association of Critical Care Nurses, 30(4), 196-203. http://dx.doi.org/10.1016/j.iccn.2013.12.006

MOH. (2011a). Country health plan 10 th Malaysia plan 2011-2015 (p. 82). Retrieved from http://www.moh.gov.my/images/gallery/Report/Country_health.pdf

MOH. (2011b). Annual Report (p. 351). Retrieved from http://www.moh.gov.my/images/gallery/publications/md/ar/2011_en.pdf

Pallant, J. (2011). SPSS Survival Manual (4th ed., p. 359). British library. Retrieved from http://scholar.google.com/scholar?hl=en\&btnG=Search\&q=intitle:SPSS+Survival+Manual\#7

Pantouvakis, A., \& Mpogiatzidis, P. (2013). The impact of internal service quality and learning organization on clinical leaders' job satisfaction in hospital care services. Leadership in Health Services, 26(1), 34-49. http://dx.doi.org/10.1108/17511871311291714

Scott, I. a, Poole, P. J., \& Jayathissa, S. (2008). Improving quality and safety of hospital care: A reappraisal and an agenda for clinically relevant reform. Internal medicine journal, 38(1), 44-55. http://dx.doi.org/10.1111/j.1445-5994.2007.01456.x

Sekaran, U., \& Bougie, R. (2010). research Methodology for Business (5th ed., p. 468). John Wiley \& Sons Ltd.

Siriwardena, A. N. (2006). Releasing the potential of health services: Translating clinical leadership into healthcare quality improvement. Quality in primary care, 14, 125-128.

Tourangeau, A. E., Cranley, L. A., \& Jeffs, L. (2006). Impact of nursing on hospital patient mortality: a focused review and related policy implications. Quality \& safety in health care, 15(1), 4-8. doi:10.1136/qshc.2005.014514

Tourangeau, A. E., Doran, D. M., McGillis Hall, L., O’Brien Pallas, L., Pringle, D., Tu, J. V, \& Cranley, L. A. (2007). Impact of hospital nursing care on 30-day mortality for acute medical patients. Journal of advanced nursing, 57(1), 32-44. http://dx.doi.org/10.1111/j.1365-2648.2006.04084.x 
Valero, C., Monteagudo, M., Llagostera, M., Bayona, X., Granollers, S., Acedo, M., ... Muñoz, L. (2009). Evaluation of a combined strategy directed towards health-care professionals and patients with chronic obstructive pulmonary disease (COPD): information and health education feedback for improving clinical monitoring and quality-of-life. BMC public health, 9(1), 442. http://dx.doi.org/10.1186/1471-2458-9-442

Van Bogaert, P., Clarke, S., Vermeyen, K., Meulemans, H., \& Van de Heyning, P. (2009). Practice environments and their associations with nurse-reported outcomes in Belgian hospitals: Development and preliminary validation of a Dutch adaptation of the Revised Nursing Work Index. International journal of nursing studies, 46(1), 54-64. http://dx.doi.org/10.1016/j.ijnurstu.2008.07.009

Van Bogaert, P., Meulemans, H., Clarke, S., Vermeyen, K., \& Van de Heyning, P. (2009). Hospital nurse practice environment, burnout, job outcomes and quality of care: Test of a structural equation model. Journal of Advanced Nursing, 65(10), 2175-2185. http://dx.doi.org/10.1111/j.1365-2648.2009.05082.x

Van Bogaert, P., Timmermans, O., Weeks, S. M., van Heusden, D., Wouters, K., \& Franck, E. (2014). Nursing unit teams matter: Impact of unit-level nurse practice environment, nurse work characteristics, and burnout on nurse reported job outcomes, and quality of care, and patient adverse events-A cross-sectional survey. International journal of nursing studies, 51(8), 1123-1134. http://dx.doi.org/10.1016/j.ijnurstu.2013.12.009

Weingart, S. N., Zhu, J., Chiappetta, L., Stuver, S. O., Schneider, E. C., Epstein, A. M., ... Weissman, J. S. (2011). Hospitalized patients' participation and its impact on quality of care and patient safety. International journal for quality in health care: journal of the International Society for Quality in Health Care / ISQua, 23(3), 269-77. http://dx.doi.org/10.1093/intqhe/mzr002

West, S. G., Aiken, L. S., \& Krull, J. L. (1996). Experimental Personality Designs: Analyzing Categorical by Continuous Variable Interactions. Journal of Personality, 64(1).

Wheelen, T. L., Hunger, J. D., Hoffman, A. N., \& Bamford, C. E. (2015). Strategic Management and Business Policy: Globalization, Innovation, and Sustainability (14th ed.). Pearson Education.

Wilson, R., Runciman, W., Gibberd, R., Harrison, B., Newby, L., \& Hamilton, J. (1995). The quality in Australian health care study. Med J Aust, 163, 458-471.

Yaakup, H., Eng, T. C., \& Shah, S. A. (2014). Does Clinical Experience Help Oncology Nursing Staff to Deal with Patient Pain Better than Nurses from other Displines? Knowledge and Attitudes Survey Amongst Nurses in a Tertiary Care in Malaysia. Asian Pacific Journal of Cancer Prevention, 15, 4885-4891.

Yang, B., Watkins, K. E., \& Marsick, V. (2004). The construct of the learning organization: dimensions, measurement and validation. Human Resource Development Quarterly, 15(1), 31-55.

You, L., Aiken, L. H., Sloane, D. M., Liu, K., He, G., Hu, Y., ... Sermeus, W. (2013). Hospital nursing, care quality, and patient satisfaction: cross-sectional surveys of nurses and patients in hospitals in China and Europe. International journal of nursing studies, 50(2), 154-161. http://dx.doi.org/10.1016/j.ijnurstu.2012.05.003

\section{Copyrights}

Copyright for this article is retained by the author(s), with first publication rights granted to the journal.

This is an open-access article distributed under the terms and conditions of the Creative Commons Attribution license (http://creativecommons.org/licenses/by/3.0/). 